\title{
The Whole New World: Nintendo's Targeting Choice
}

\author{
Alexander Rusetski, Ph.D. York University, Toronto, Canada
}

\begin{abstract}
The case is set at the end of 2006 when Nintendo and Sony were preparing to launch their seventh generation gaming consoles while Microsoft had its console on the market for more than a year. Starting with the fifth generation (when the PlayStation was first introduced), the competition among the three main players in the market was focused mostly at the segment of "hard-core" gamers - young adults spending substantial time playing elaborate games. By 2006 Nintendo was hopelessly losing the competition in this segment. The company had to come up with a bold move to remain relevant in the industry. So, rather than staying within the confines of the familiar segment, Nintendo decided to target its new console to a market that was all but neglected in the previous decade - the casual gamers: kids, women, older folks, and families. The case is used as a basis for the discussion of targeting decision process.
\end{abstract}

Keywords: Brand management; positioning; new product development; Microsoft Xbox 360; Sony PlayStation3; Nintendo Wii

\section{PART 1: NINTENDO'S CHOICE}

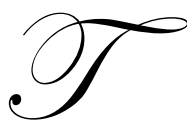

here are many epic stories of companies battling for a particular market putting tremendous resources and their future on the line: Sony Betacam vs. VHS format; Pepsi vs. Coke; Apple vs. Microsoft. Attractive markets with clearly outlined borders confine the efforts of few competitors creating drama comparable to sports tournaments.

Video gaming is one such market. More specifically - the market of gaming consoles: devices that are being attached to TV sets allowing to play games on screen. The market was pioneered in 1972 by the US company Magnavox and by early 1980s was developing rapidly with companies like Atari, Mattel, Coleco, and others fighting bitterly for a piece of sales. At that time, virtually any party could write a game for any of the competing consoles hardware manufacturers did not control third party offerings. The "North American game crash" of 1983-84 precipitated by huge supply of poor quality systems and lousy third-party games wiped out most of US manufacturers of gaming consoles and radically reduced the number of players in the market. As the depressed market was recovering in 1987 the Japanese manufacturer Nintendo became the market leader with its immensely popular Nintendo Gaming System.

In the 1980's gaming console manufacturers targeted mainly children. Game graphics was mostly twodimensional, games were simple and easy to learn, but like any game they were very attractive for kids. Nintendo introduced several extremely successful titles including the still popular character Mario. The company was also one of the first to introduce hardware locks on its systems that only allowed playing licensed games that were developed either by Nintendo or by licensed third parties who had to meet Nintendo's strict quality standards and pay it licensing fees.

By the mid-nineties Nintendo was an undisputed leader in gaming consoles, outselling its competitors SEGA and NEC by a substantial margin. That is until 1994, when Sony entered the market with its PlayStation. Instead of kids Sony decided to target the young adults market, a segment of population who grew up playing previous generation consoles and now was ready to move on to different kinds of games - more visual, more dynamic, sometimes more violent. Sony's goal was to move gaming consoles from kids' rooms to living rooms. And the market responded with enthusiasm: very soon PlayStation was outselling Nintendo three to one. 
Ironically, Nintendo to an extent facilitated the appearance of its strongest rival: in 1986-1991 the two companies in partnership were developing a CD drive for Nintendo's next generation console. Two parties could not decide on how revenues would be split so Nintendo broke the partnership. Infuriated Sony's president Norio Ohga decided to strike back by developing and launching a console to compete with Nintendo. So the most successful gaming console brand - PlayStation - was born.

Things went progressively worse for Nintendo when Sony launched its next generation console PlayStation2. Cleverly, Sony included the ability to play DVD movies, making the system more of a universal video device and giving young adults all the more reasons to purchase it: it was the time when DVD was actively replacing VHS as a primary format for home video. To make matters even worse, another giant - Microsoft - joined the battle in 2001 with its Xbox. While not as popular as PlayStation 2, Xbox offered some unique features like hard drive for saving games and Ethernet connection for online gaming via Microsoft's paid service Xbox Live.

New entrants added a lot of power to once basic devices. Nintendo tried to respond with new systems, most notably Nintendo GameCube, but specifications were not too exciting plus the company was slowed down by its "childish" image that has become all but irrelevant in the era of "M"-rated games. Even though several developers adopted their titles for Nintendo GameCube platform, "serious" gamers still saw it as inferior to Xbox and especially PlayStation 2. To keep up with its competitors Nintendo had to more and more resort to price cuts, which again did not add to its brand's cachet.

By the end of 2005 many analysts dismissed Nintendo as a "has been". PlayStation2 was dominating the market and Nintendo even fell behind the Xbox. As the next, so-called seventh generation of gaming consoles was about to be launched, Nintendo's future in gaming consoles was quite gloomy.

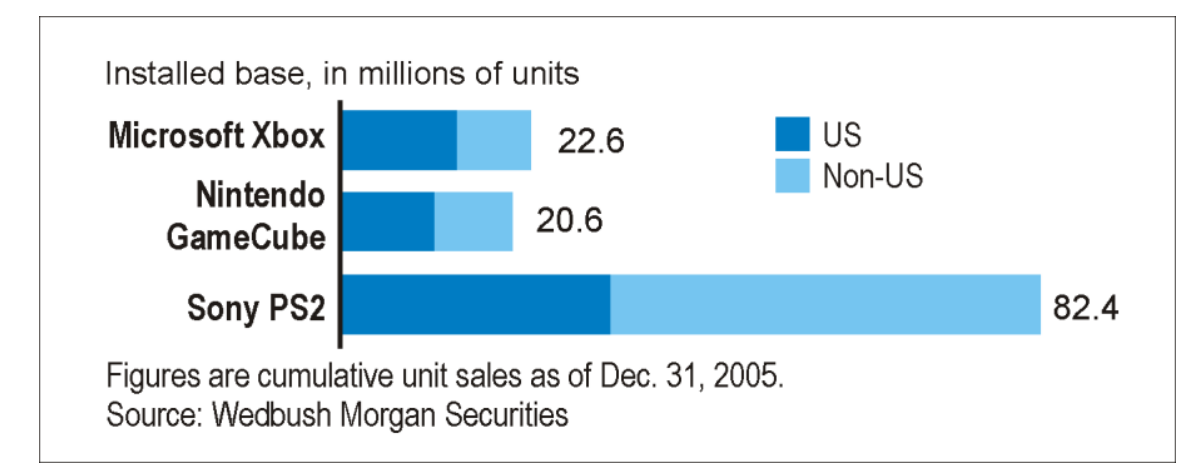

Figure 1: Installed gaming consoles worldwide, 2006 (Adapted from The Wall Street Journal)

At the same time, Nintendo's position in handheld gaming systems remained strong. Nintendo pioneered this market in 1989 with its Game Boy that became an instant hit. Although Sony tried to penetrate this market by launching its PlayStation Portable (PSP) device in 2005, it could not replicate the success it had with consoles. On September 15, 2006 Nintendo announced that it still held 70\% market share in handheld devices represented by its Nintendo DS and Game Boy Advance models. Moreover, company revenues were growing rapidly driven by Nintendo DS sales. That brought Nintendo's bottom line up too: in 2006 operating profit was expected to rise 38\% compared to 2005. But this success could not overshadow the problems in Nintendo's core business.

Table 1: Major handheld gaming devices in 2006

\begin{tabular}{lll} 
& Nintendo DS Lite & Sony PlayStation Portable \\
\hline Price (in the U.S.): & $\$ 129.99$ & $\$ 299$ \\
\hline Weight: & $218 \mathrm{~g}$ & $280 \mathrm{~g}$ \\
\hline Screens: & Two 3" $(77 \mathrm{~mm})$ LCD screens & 4.3 " $(110 \mathrm{~mm})$ LCD screen \\
\hline Features: & WiFi connectivity & $\begin{array}{l}\text { WiFi and infrared connectivity, movies play } \\
\text { back capability (requires unique UMD disks) }\end{array}$ \\
\hline Battery: & Battery life: 5-19 hours & Battery life: 4-6 hours \\
\hline
\end{tabular}


In 2000-2005 the TV and computer technologies were advancing rapidly. The introduction and quick spread of digital high definition television (HDTV) format was one of the major factors. New TV sets produced much crisper pictures and this opened new possibilities for development of exciting and visually appealing games to satisfy growing demands of hard-core gamers. High definition format also demanded more processing power, and that meant more R\&D expenditures. Both Sony and Microsoft, large diversified technological empires, could afford significant investments in development of new technologies, while for Nintendo that was a serious burden.

Microsoft was the first one to launch the seventh generation system - the Xbox 360 - in November 2005. New console rendered games in stunning high definition format (1080p), could be used as a DVD player and supported online gaming via Xbox Live paid service. With several very popular games that were unique for this platform - most noticeable "Halo" and "Gears of War" - the Xbox 360 was immediately successful. The next round of console wars was opened.

And the war promised to be fierce. The video-game consoles industry still appealed to a large population of enthusiasts who were willing to pay significant money to play the "latest and the best". Over the years, both Microsoft and Sony developed a huge base of loyal fans, mostly young male adults with sufficient funds to afford expensive hardware and games at $\$ 50-\$ 70$ apiece. The size of this market in 2006 was estimated to be $\$ 16$ billion. With just three players in it, any shift in balance meant serious money.

Microsoft had a significant advantage over the two rivals as it launched its Xbox 360 a year ahead of the competition. That allowed Microsoft to capture attention of gamers who wanted higher performance than provided by older PlayStation 2 and GameCube. Microsoft expected to sell 10 million Xbox 360s before newer PS3 or Wii hit the shelves.

Sony scheduled the launch of its new PlayStation 3 on November 17, 2006. The company made a strong bet on the features of its new console, one of which was a built-in Blu-ray disk player. This new media format allowed storing and playing back high-definition movies, making PS3 a real new generation home entertainment system. But it was also a risky bet because Blu-ray was not an industry standard yet. Competing HD DVD format was backed by Toshiba and Microsoft, and it was a question of time which one would win $^{1}$. Sony expected to ship 2 million units of PS3 before the year end of 2006.

In the face of such strong moves by its competitors, Nintendo had to respond either with blunt force offering even more powerful system or with some creative strategic move. When specifications of the Nintendo's $7^{\text {th }}$ generation console named Wii (read "wee") were unveiled it immediately became apparent that the company chose the creative approach.

Table 2: Seventh generation video gaming consoles and their characteristics

\begin{tabular}{|c|c|c|c|}
\hline & Microsoft Xbox 360 & Sony PlayStation3 & Nintendo Wii \\
\hline Price (US, 2006): & $\$ 300-\$ 400$ & $\$ 499-\$ 599$ & $\$ 250$ \\
\hline Launched: & $11 / 22 / 2005$ & Scheduled 11/17/2006 & Scheduled 11/19/2006 \\
\hline Specifications: & $\begin{array}{l}\text { 512MB memory, three-core } \\
\text { IBM processor }\end{array}$ & $\begin{array}{l}\text { 512MB memory, seven core Cell } \\
\text { processor }\end{array}$ & 512 memory, IBM processor \\
\hline Features: & $\begin{array}{l}\text { High Definition support, DVD } \\
\text { plaier, optional 20GB hard } \\
\text { drive, Ethernet and optional } \\
\text { WiFi connectivity }\end{array}$ & $\begin{array}{l}\text { High Definition support, Blu-ray } \\
\text { player, } 20 \text { or } 60 \mathrm{~GB} \text { hard drive, } \\
\text { Ethernet }\end{array}$ & $\begin{array}{l}\text { No High Definition support, } \\
\text { custom format disks (external } \\
\text { DVD is optional), WiFi } \\
\text { connectivity. }\end{array}$ \\
\hline
\end{tabular}

The Wii was the only new generation console that did not support HDTV format. It was also strictly a gaming console without a hard drive or a built in ability to play DVDs or other media. What made Wii unique was

\footnotetext{
${ }^{1}$ For a while the two formats co-existed, with movies being released both in Blu-ray and HD DVD formats. The high definition media format war was decided in favor of Blu-ray only in 2008 when several major studios and retailers abandoned the HD DVD format.
} 
an innovative controller responding to players' movements. The new controller made gaming more intuitive, easy to learn and much more fun to play. Players now had to move rather than sit for hours in front of TVs - a healthier alternative to traditional video gaming. Most noticeably, the new console was 17\% less expensive than the cheapest version of the Xbox 360 and cost only half of what the simplest PlayStation 3 would. The launch of the Wii was scheduled on November 19, just two days after the scheduled launch of PlayStation 3.

Industry observers found such approach strange, but Nintendo had high hopes. Just like Sony twelve years ago, Nintendo noticed the emergence of a new market - in fact, several new markets. First, in the time when most popular games were the ones aimed at mature audiences, young kids were clearly underserved. Not many parents were willing to purchase relatively expensive systems just to open to their kids the world of violence, blood and gore. Nintendo's positions in this market were traditionally strong. One of the reasons: Nintendo's family-friendly image and its emphasis on game play simplicity. Unlike Microsoft and Sony who had to rely on third-party game developers, Nintendo was developing its signature games in-house, and the firm traditionally imposed stricter standards on third-party developers as well.

But children were not the only market that Nintendo intended to target. The company's success with handheld gaming devices prompted attention to two other categories of potential buyers. In May 2005 Nintendo added to its collection of DS games a new title: "Brain Age". Unlike action-packed "kill-them-all" titles, this one was a set of riddles and math problems aimed at exercising the brain. This game was built around the theory that a series of rapid-fire, simple problems such as basic arithmetic would engage the entire brain, keeping the mind agile with the age. This was not a trivial theory. One of the largest generations that supported U.S. economy for past half century -78 million of baby boomers - were rapidly approaching the senior citizen status. Not many of them were thrilled with the prospective of their mental capabilities declining and were interested not just in playing games, but in "mental exercise". "Brain age" for handheld DS was selling fast and Nintendo expected that offering a stationary platform for such exercises can be attractive for a large segment of ageing customers.

Another kind of gamers who found Nintendo handhelds attractive were women. Simplicity of Nintendo games made it easier for women to learn them without sacrificing valuable time. Nintendo offered more games that did not require skills, experience, and dedication to enjoy them. Plus their generally less violent nature made them more suitable for family environment, where children could play together with their parents. A clever design of the motion controller also suggested a healthier way of gaming that provided at least some exercise to kids.

Overall, rather than keep fighting for the share of traditional gaming market, Nintendo decided to bet on "casual" gamers. The big question was whether that segment had the same revenue and profit potential as traditional gamers. In the hindsight it looks like a sure bet, but in 2005 and 2006 it was far from that. Even after Wii's specifications were announced and Nintendo's targeting became apparent two other major players did nothing to shift their focus away from traditional, young adult gamers. Microsoft announced a cheap, stripped down version of Xbox 360 to pre-empt Wii's launch, but this move did not signify a change in the targeting, just an attempt to hurt a competitor. Sony continued to position its PlayStation 3 as a premium, most powerful gaming system emphasizing unparalleled realism and game immersion in its advertisements.

As the holiday season of 2006 was approaching, industry observers were speculating whether Nintendo's targeting choice was correct. Not only it was not clear how large the casual gamers segment was, but low-cost approach created serious doubts regarding the profitability of Nintendo's strategy. Nintendo's plan was to ship 4 million Wiis by the end of 2006 and Nintendo of America President Reggie Fils-Aime was predicting shortages due to excessive demand. Yet observers agreed that reaching this number was an ambitious goal considering that the console was scheduled to be the latest entrant in the market. 


\section{APPENDICES}

\section{Appendix 1: Selected accounting data for major players, 2004-05}

\begin{tabular}{|l|r|r|}
\hline Microsoft Corporation & $\mathbf{2 0 0 5}$ & $\mathbf{2 0 0 4}$ \\
\hline Revenue (\$ mil) & $39,788.0$ & $36,835.0$ \\
\hline Gross Profit (\$ mil.) & $33,588.0$ & $30,119.0$ \\
\hline Total Net Income (\$ mil.) & $12,254.0$ & $8,168.0$ \\
\hline Total assets & $70,815.0$ & $92,389.0$ \\
\hline Cash & $37,751.0$ & $60,592.0$ \\
\hline Net Fixed Assets & $2,346.0$ & $2,326.0$ \\
\hline Total liabilities & $22,700.0$ & $17,564.0$ \\
\hline
\end{tabular}

\begin{tabular}{|l|r|r|}
\hline Nintendo Ltd. & $\mathbf{2 0 0 5}$ & $\mathbf{2 0 0 4}^{\mathbf{2}}$ \\
\hline Revenue (\$ mil) & $4,348.9$ & $4,812.9$ \\
\hline Gross Profit (\$ mil.) & $1,837.8$ & $2,031.6$ \\
\hline Total Net Income (\$ mil.) & 840.8 & 816.9 \\
\hline Total assets & $9,920.5$ & $10,584.0$ \\
\hline Cash & $5,274.7$ & $7,408.7$ \\
\hline Net Fixed Assets & 478.4 & 508.6 \\
\hline Total liabilities & $1,593.4$ & $1,970.0$ \\
\hline
\end{tabular}

\begin{tabular}{|l|c|c|}
\hline Sony Ltd. & $\mathbf{2 0 0 5}$ & $\mathbf{2 0 0 4}$ \\
\hline Revenue (\$ mil) & $66,584.4$ & $71,215.7$ \\
\hline Gross Profit (\$ mil.) & $15,595.4$ & $23,162.8$ \\
\hline Total Net Income (\$ mil.) & $1,523.7$ & 840.8 \\
\hline Total assets & $88,341.6$ & $86,361.3$ \\
\hline Cash & $11,539.4$ & $10,721.9$ \\
\hline Net Fixed Assets & $12,763.3$ & $15,407.0$ \\
\hline Total liabilities & $61,647.5$ & $63,770.3$ \\
\hline
\end{tabular}

Source: Hoovers.com

\footnotetext{
${ }^{2}$ Nintendo's fiscal year ends on March $31^{\text {st }}$, so the numbers for 2004 are from the annual report for the fiscal year that ended on March 31, 2005.
} 
Appendix 2: Nintendo Wii printed ad, a part of their 2006 "My Wii story" campaign
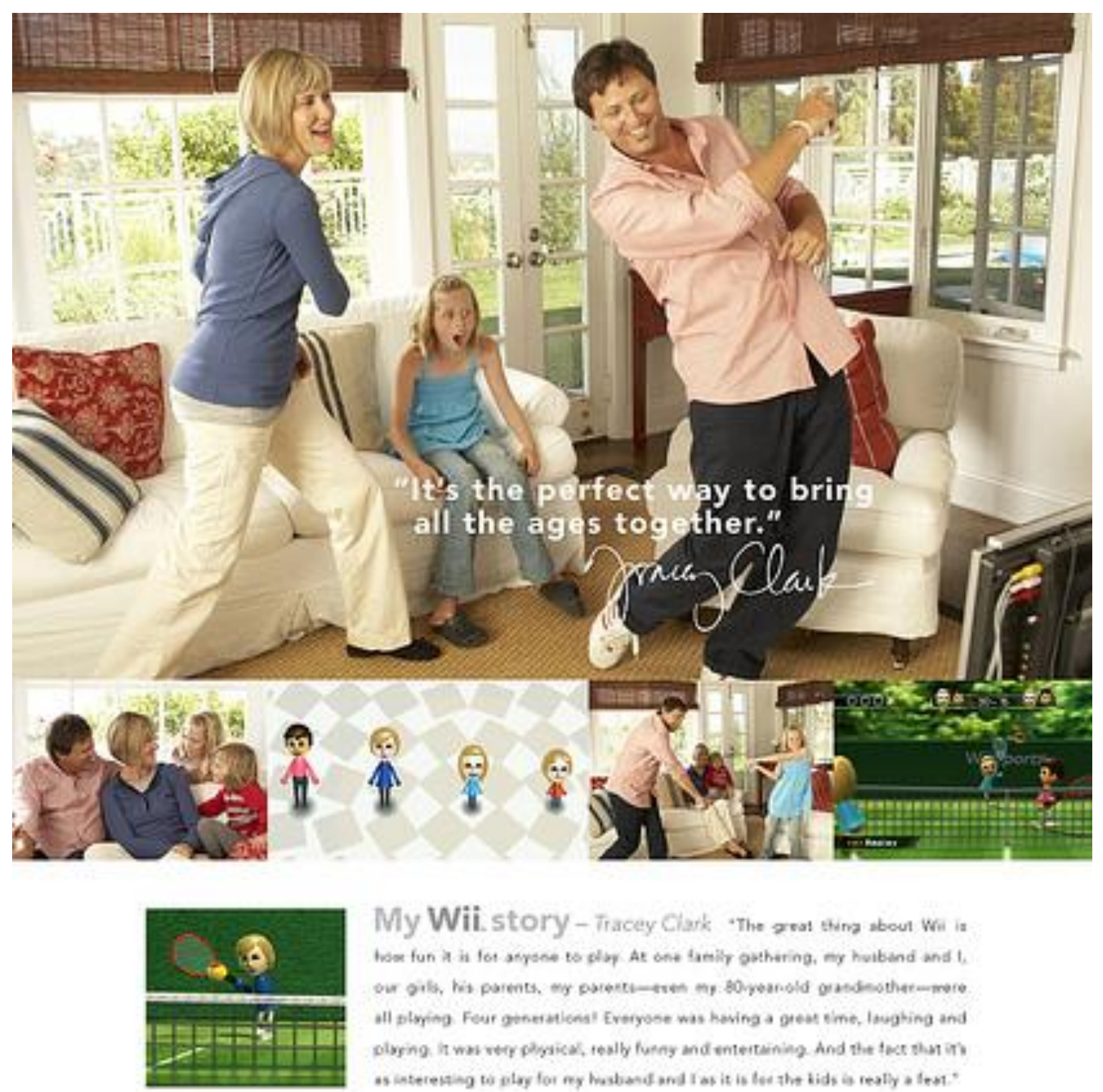

My Wii. story - Tracey Clark "The great thim aboul Wil is

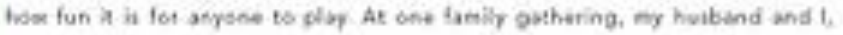

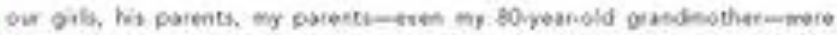

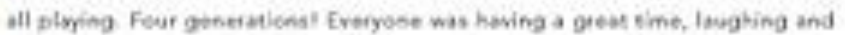

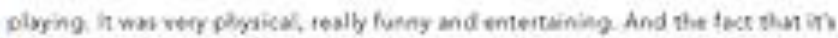

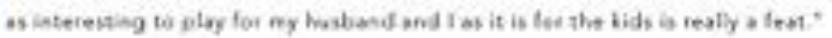


Appendix 3: PlayStation 3 printed ads, 2006
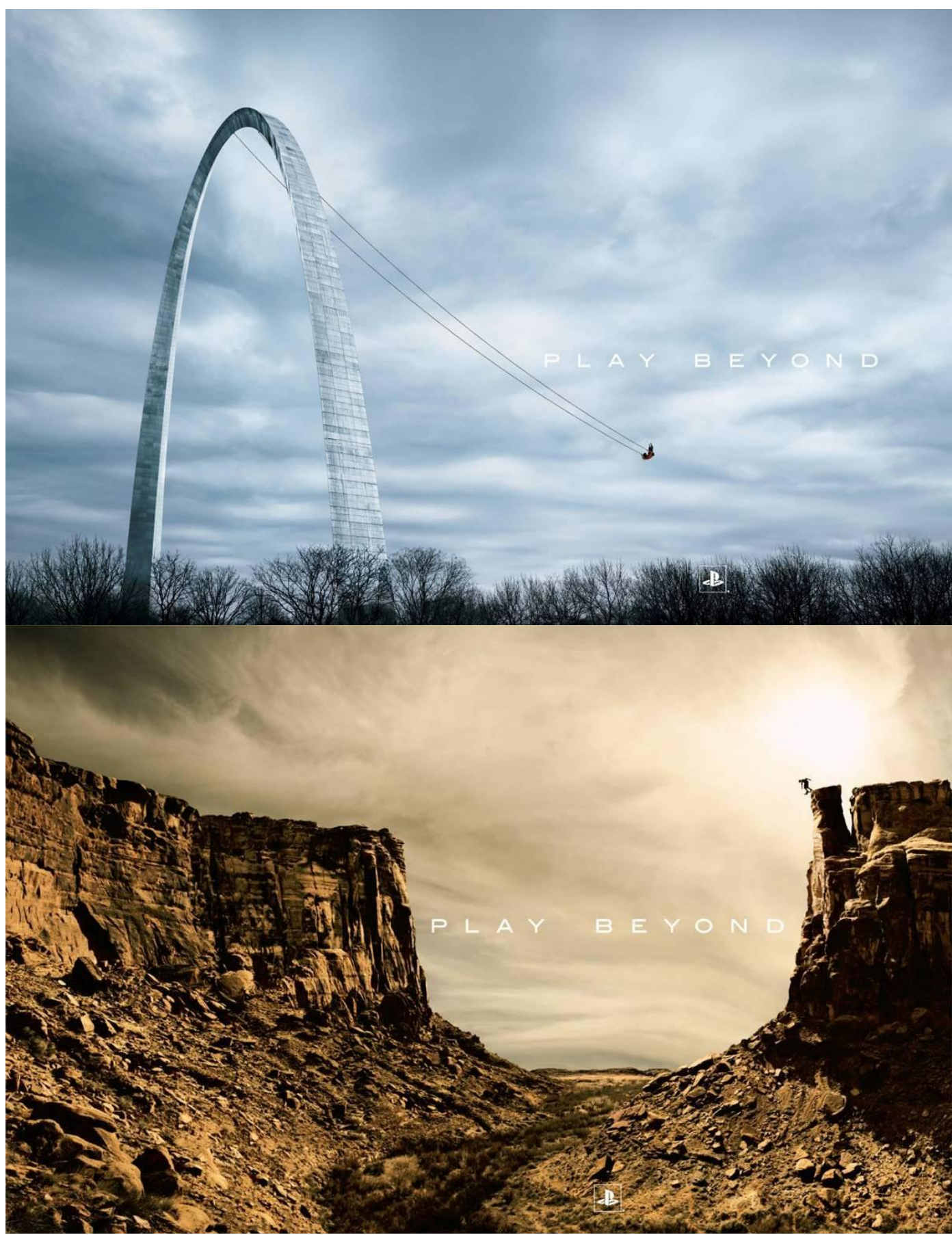


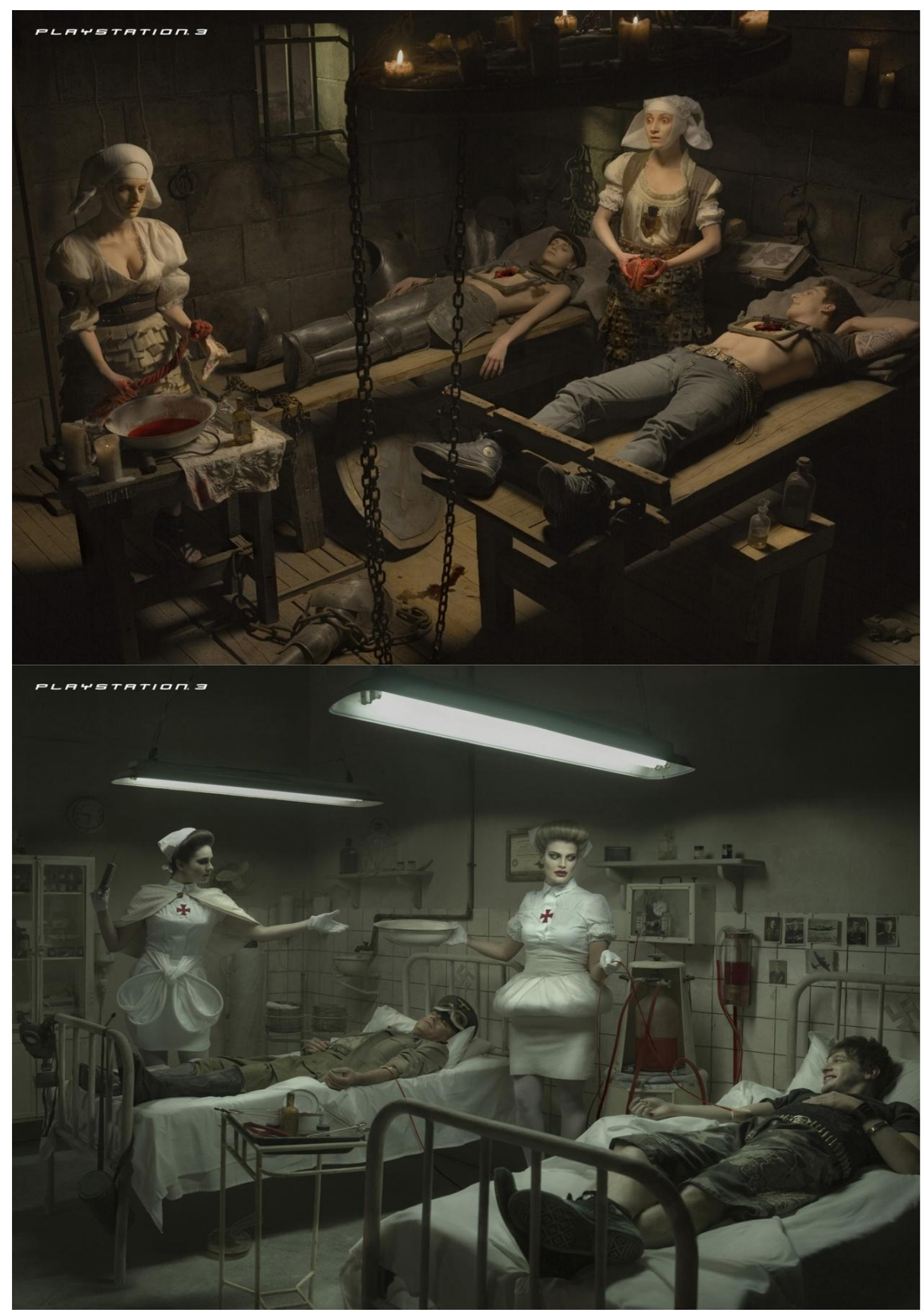




\section{Epilogue: The Whole New World}

Industry experts' doubts were resolved in late November 2006, when Nintendo Wii was launched two days after Sony PlayStation 3. These long anticipated events proved once again that no battle plan survives the first contact with the enemy. Advertising campaigns launched by Sony and Nintendo to prepare the public for their new products created immense hype both among traditional gamers and the general public. PlayStation 3 launched the first on November $17^{\text {th }}, 2006$, and within a day it was sold out. This could be seen as a sign of a success, but in extremely competitive environment not being able to satisfy demand was in fact a sign of a trouble. Sony could not keep up with the demand, mostly due to the shortage of Blu-ray drives. Only about $60 \%$ of the planned 400,000 consoles reached American stores in time for the launch. With significant unsatisfied demand, the attention of the market shifted to the Wii. Ironically, many traditional gamers, especially those who could not get themselves a PlayStation 3, were eager to try Wii's new motion controller. By the end of 2006 Nintendo sold 1.25 million units in the US and Canada (3.19 million worldwide). This high rate of sales continued in coming months, and in September 2007 Wii surpassed the Xbox 360 in terms of units sold, even though the Microsoft's console has been launched one year ahead of Wii. For the first time in 17 years Nintendo became a gaming consoles market leader again!

Wii turned out not only to be more successful than its rivals, but also the most profitable. At the beginning of 2010, research company iSuppli estimated that in November 2005 when retail price of Xbox 360 was $\$ 399$ the cost of its components was $\$ 470$. PlayStation 3's components cost $\$ 840$ and $\$ 805$ when its retail prices were $\$ 599$ and $\$ 499$ for 60GB and 20GB models respectively (November 2006) ${ }^{3}$. So with every unit sold Microsoft was losing at least $\$ 71$ and Sony from $\$ 241$ to $\$ 305$. At the same time, in December 2006 Wii's components cost only $\$ 158.30^{4}$, more than $\$ 90$ less than the retail price.

As Nintendo expected, the Wii became popular with families and to an extent - with women and seniors. Among the main drivers of the success was the motion controller which created completely different gaming experience. But even more important was clever selection of games which focused on motion and exercise, being at the same time simple to learn and easy to play. This allowed the whole family to enjoy playing - and subsequently interacting with each other: an experience vastly different from families with basement-dwelling hard-core gamers. Nintendo's focus on exercise was especially positive against the backdrop of growing public concerns about child obesity and the impact of video games on it. Now parents could purchase video consoles without the feeling that they are putting their children's health at risk.

In one smart move, Nintendo demonstrated that in the constantly changing market there always was the possibility to find new segments. And sometimes these segments do not have to be obscure small groups of people. Sometimes a majority of potential market can be underserved opening the whole new world of possibilities.

Appendix 1: Selected accounting data, Nintendo Ltd. 2005-2008

(Nintendo's fiscal year ends in March, so "Mar 2008" actually reflects company's sales in 2007 calendar year)

\begin{tabular}{|l|c|c|c|c|}
\hline Nintendo Ltd. & Mar 2008 & Mar 2007 & Mar 2006 & Mar 2005 \\
\hline Revenue (\$ mil) & $16,843.0$ & $8,200.1$ & $4,348.9$ & $4,812.9$ \\
\hline Gross Profit (\$ mil.) & $7,050.3$ & $3,375.0$ & $1,837.8$ & $2,031.6$ \\
\hline Total Net Income (\$ mil.) & $2,591.7$ & $1,478.7$ & 840.8 & 816.9 \\
\hline
\end{tabular}

Source: Nintendo Annual reports

\footnotetext{
${ }^{3}$ http://images.businessweek.com/ss/07/01/0118 teardown/index.htm?technology+slideshows (April 15, 2010)

4 http://www.engadget.com/2006/12/15/wii-manufacturing-costs-ring-up-to-just-158/ (April 15, 2010) 
Appendix 2: Nintendo Stock price changes (2002-2008)

NTDY

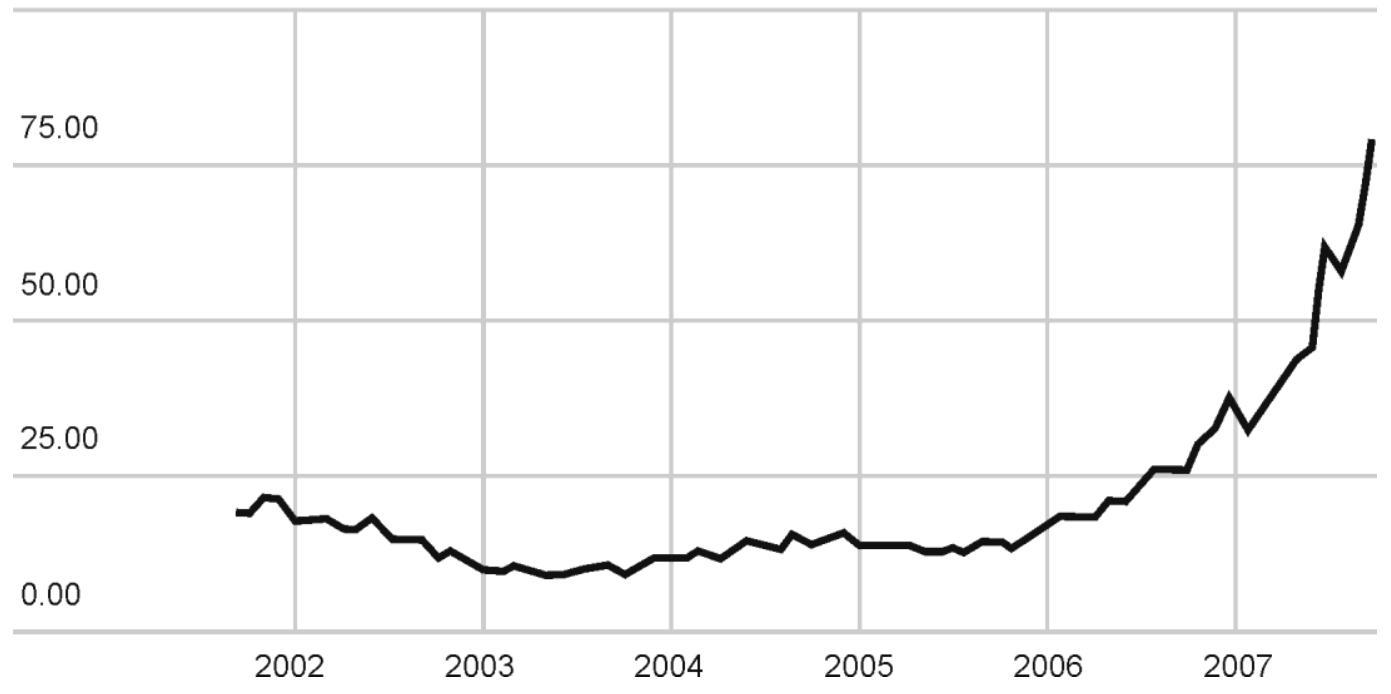

\section{AUTHOR INFORMATION}

Alexander Rusetski is Assistant Professor of Marketing at York University's School of Administrative Studies. His research in strategic marketing and decision-making appeared in the Journal of International Business Studies and Journal of Strategic Marketing. E-mail: arusetsk@ yorku.ca.

\section{REFERENCES}

1. $\quad$ Arnst, C. (2006). Chicken Soup for The Aging Brain. [Article]. BusinessWeek (4002), 94-96.

2. Bremner, B. (2006). Will Nintendo's Wii Strategy Score? [Article]. BusinessWeek Online, 22-22.

3. Hartley, M. (2011, June 7). Nintendo kicks off next generation of console wars with Wii U, Financial Post.

4. Kane, Y. I. (2006, July 25). Nintendo's Net Receives Lift From Brisk DS Sales, The Wall Street Journal.

5. Kane, Y. I., \& Wingfield, N. (2006, November 2). Amid Videogame Arms Race, Nintendo Slows Things Down, The Wall Street Journal.

6. Loftus, T. (2011). Nintendo Fails to Level Up. Retrieved from http://blogs.wsj.com/digits/2011/10/27/techtoday-nintendo-fails-to-level-up/

7. Mann, J. (2006). Nintendo expects supply shortage of Wii Retrieved November 1, 2006, from http://www.techspot.com/news/23415-nintendo-expects-supply-shortage-of-wii.html

8. Sanchanta, M. (2007, September 12). Nintendo's Wii takes console lead, Financial Post.

9. Wakabayashi, D. (2011, October 28). Nintendo Dragged Down by Sluggish Wii Sales, The Wall Street Journal.

10. Wingfield, N. (2011, July 29). Nintendo: Apple's Latest Prey, The Wall Street Journal.

11. Wingfield, N., \& Wakabayashi, D. (2011, June 8). Next Wii to Play Off the Tablet Craze, The Wall Street Journal.

12. Woo, S. (2011). Nintendo Game Chief Sees Better Times Ahead. Retrieved from http://blogs.wsj.com/digits/2011/12/08/nintendo-game-chief-sees-better-times-ahead/ 


\section{The Whole New World: Nintendo's Targeting Choice: Teaching Notes}

Alexander Rusetski, York University, Toronto, Canada

\section{CASE OVERVIEW}

The case is set up in the end of 2006 when Nintendo and Sony were preparing to launch their seventh generation gaming consoles while Microsoft had its console on the market for more than a year. Starting with the fifth generation (when the PlayStation was first introduced), the competition among the three main players in the market was focused at the segment of "hardcore" gamers - young adults spending substantial time playing elaborate games. By 2006 Nintendo was hopelessly losing the competition in this segment. The company had to come up with a bold move to remain relevant in the industry. So, rather than staying within the confines of the familiar segment, Nintendo decided to target its new console to a market that was all but neglected in the previous decade - the casual gamers: kids, women, older folks, and families.

\section{PURPOSE OF THE CASE AND OBJECTIVES}

The case is used as a basis for the discussion of targeting decision process. The discussion should reveal to the students the following points:

1) The importance of external analysis, including the most general, environmental analysis. It was the understanding of the global demographic trends that allowed Nintendo to realize the existence and potential of segments other than traditionally targeted "hard-core" gamers.

2) The importance of creative approach to market segmentation. Segments are not given, they are a result of a managers' vision of the market. While hard-core gamers could have been further segmented based on their gaming preferences, Nintendo took a step back and suggested the existence of other segments outside of the traditional target.

3) The uncertainties associated with changing market targets. At the time of the Wii launch, the potential of casual gamers was far from clear. Two sequential discussions - one about Sony targeting young adults instead of kids and another about Nintendo targeting "casuals" instead of hard-cores should demonstrate the steps, the assumptions and uncertainties embedded in marketing strategy decisions.

The secondary objectives include:

1) Train the students to evaluate the business model of an enterprise before analyzing the situation.

2) Show the students the importance of an appropriate product design for a particular market.

3) Show the need to make and live with assumptions when making strategic decisions.

\section{Suggested courses}

This case is being used in the capstone Marketing Strategy course, but being not too challenging and dealing with an interesting and engaging industry it can be used in earlier stages of a marketing curriculum.

\section{Suggested Discussion Questions}

Case discussion can be started with a brief overview of how Nintendo came to be the major player in the industry in 90's and how Sony managed to take the leadership away. 
The important key to Nintendo's success was the establishment of control over the software available for their consoles. Only licensed software could be used with Nintendo consoles. This move changed the business model for the industry: now a hardware manufacturer was making money not only on hardware sales but mainly on sales and license fees of games.

Sony managed to steal the leading position by timely noticing the emergence of a new and potentially more profitable market of young adults, who unlike children could make their own purchasing decisions and had sources of income, allowing them to spend more on games. An interesting observation that can be made is that Sony with its PlayStation 2 made the first step toward turning a gaming console into an entertainment system - by enabling the system to play DVD disks. This gave young adults all the more reasons to purchase Sony systems.

Next, the discussion can shift toward the following questions:

1) What major challenge did marketers at Nintendo faced when determining their next move in console wars? What choices did they have in the face of competition?

The major challenge for Nintendo was that it was facing two powerful competitors and that for the past several years it was losing the market share to the competition. Market share data shows that the number of installed Nintendo consoles was less than $17 \%$ of the market, less than Xbox, the last brand to join the consoles war.

In the face of such competition Nintendo had only two major choices: either fight or run. Fight would have meant focusing on hard-core gamers and attempting to beat Sony and Microsoft in terms of performance. Given the expensive components required for high-performance systems, Nintendo most likely would have been selling its consoles at a loss. Additionally, Nintendo's kids-friendly image worked against them in the market that was focused on violent, M-rated games.

An alternative was to run, meaning moving away from direct, head-to-head competition by seeking a different segment, not served by the Xbox or PlayStation.

It is important to show to the students that Nintendo's choice was actually to run.

Compare Nintendo to its main competitors in 2005-06:

a. What targeting approaches were utilized by the three firms?

b. Was the positioning different among the competitors?

c. Compare financial situations of competing firms. Which firm has more resources? Which company is more efficient in its operations?

Nintendo was facing two extremely powerful competitors - Microsoft and Sony. At the time of the case, Sony and Microsoft were using a single segment concentration approach, focusing mostly on hard-core gamers. This made advertising and promotion streamlined for them with a single, consistent message. Nintendo, on the other hand, used selective specialization, targeting both hard-core gamers and kids. The problem with such an approach is that it can (and most likely did) create confusion among customers because the needs of the two segments are different, requiring different messages in advertising campaigns aimed at each segment.

All three companies used a similar positioning, offering their product as a gaming console, with performance and games selection used as points of difference. Even though initial success of Sony PlayStation was to an extent attributed to its ability to play DVDs, this was not the focus the PlayStation advertising, and especially given that this ability soon became available on the Xbox (Nintendo never included the DVD playback capability in its systems). The similar positioning is indicative of the head-to-head competition with very little differentiation.

Analysis of financial data of the two companies would reveal that Nintendo was substantially smaller, albeit showing better overall profitability than Sony. Both major competitors were multi-business companies with long history of successful innovation in consumer electronics. Unlike Nintendo, both companies could shift substantial resources and knowledge among their units, realizing significant synergies. 
3) What is the essence of Nintendo's strategy with Wii?

a. How did they segment the market?

b. Whom did they decide to target?

c. How is Nintendo Wii positioned?

The announcement of the Wii indicated the shift in Nintendo's marketing strategy. It appears that the company looked at the market somewhat differently than before, and instead of pursuing smaller, more specialized segments has identified two major segments: the hard-core and casual gamers. In a bold move, Nintendo abandoned the hard-core gamers segment and focused on casual gamers. Within the casual segment, more specific categories of customers were identified: children, women, seniors, and families. While needs and wants of each sub-segment were somewhat different, they did not carry an inherent contradiction (like the needs of children and hard-core gamers) and therefore allowed the marketing campaign to be consistent and more effective.

Unlike the PlayStation 3 which featured the Blu-ray player and the Xbox 360 that had the DVD playback capability, the Wii was designed strictly as a gaming console and was positioned as such. The main difference from the competitors was that the Wii was from the outset positioned as a FAMILY gaming system as opposed to performance gaming system.

4) What market trends did Nintendo try to capitalize on?

Nintendo capitalized on several megatrends. The first trend was the increased familiarity of the population with video games. If hard-core gamers can be seen as Innovators or Early adopters, casual gamers can be seen as the majority. Among other categories, this group of customers included women, who being more educated and better employed were ready to use Wii if not for gaming then for exercise. Increase adoption of video gaming among women also made mothers potentially more interested in participating in their kids' games giving families more chances to spend time together. Another important category of customers were ageing, but still active people interested in mental and physical exercise. Finally, the creative motion controller of the Wii was a perfect response to parents' concern about the health of the children who were spending long hour in front of TVs without much exercise.

The fact that Nintendo managed to uncover the new segments of gamers was due mostly to their analysis of the environment, mostly of the demographic environment. Changes in the market that Nintendo was capitalizing on were not specific to the video gaming industry but were the part of global megatrends affecting currently numerous industries and markets. The success of Wii demonstrates the importance and relevance of the careful situation analysis on all levels - environment, industry, competition, and firm.

5) What were the risks associated with Nintendo's new targeting?

At this stage it is important to convince the students not to rely on their knowledge of the outcome of the Wii launch, but to consider the situation impartially. A segment's attractiveness is evaluated against five major criteria: size, growth rate, profitability, competitive situation, and a firm's own advantage in the segment. While competitive pressures in the segment of casual gamers were minimal and Nintendo with its family-friendly image was very relevant for them, a serious uncertainty was related to the first three criteria. Indeed, while Innovators and Early Adopters usually comprise only about $16 \%$ of potential buyers, it was not clear whether the adoption process in video gaming had reached the point where early and late majority (usually about $68 \%$ of a market) were ready to join the gaming community. Similarly, the growth rate of the casual segment was also an unknown. And probably the largest risk was related to the profitability of the segment. Hard-core gamers were willing to pay premiums for the latest and best products. For casual gamers a console was not a necessity. So charging high premiums for hardware was not possible and games should have been affordable too. The main source of profits in such situation is economies of scales - Nintendo needed high volumes of sales to build up rapidly, otherwise they risked losing money.

The uncertainty with the profitability was addressed by Nintendo along two related directions. They have established a relatively low price for its product. This move was intended to attract customers with even modest 
disposable incomes. Launching the Wii during the Christmas shopping season made it a good candidate for a Christmas gift. The initial sales helped to generate buzz among potential customers, and sales remained strong in the coming years. At the same time, Nintendo made sure that manufacturing costs of the Wii were low enough. This was achieved by setting performance characteristics of the Wii substantially lower than those of its competitors. Given the Wii's target market, this was a reasonable approach allowing it to save on research and development and on components' cost. While both Xbox 360 and PlayStation were sold at loss, the cost of Wii components was lower than its price, and economies of scale and the experience curve effect were expected to lower these costs even further.

\section{CONCLUSION}

This case is a vivid example of a consistent marketing strategy that was based on a thorough situation analysis. The story of Wii shows how a product that fits its target's needs and is supported by a relevant and consistent marketing campaign can change a company from being and industry underdog to being an undisputed leader.

\section{A twist to the case: A possible further discussion}

While the Wii has been a clear success for Nintendo, it is interesting to show the students how short-lived the success can be and how dangerous betting on a particular market segment can be.

Since mid-2007 Nntendo's stock price showed a consistent downward trend. Sales of both the Wii and hand-held gaming devices were declining.

Some blamed this on the obsolete design on of Nintendo products. Indeed, the lack of HD support on Wii was a benefit in 2006 when high definition TVs were a novelty, priced at a premium and usually purchased for family entertainment. By 2008 the price of HD TVs dropped significantly and small, inexpensive models suitable for kids' rooms appeared. Wii's slightly blurred graphics became an apparent disadvantage.

\section{NTDY}

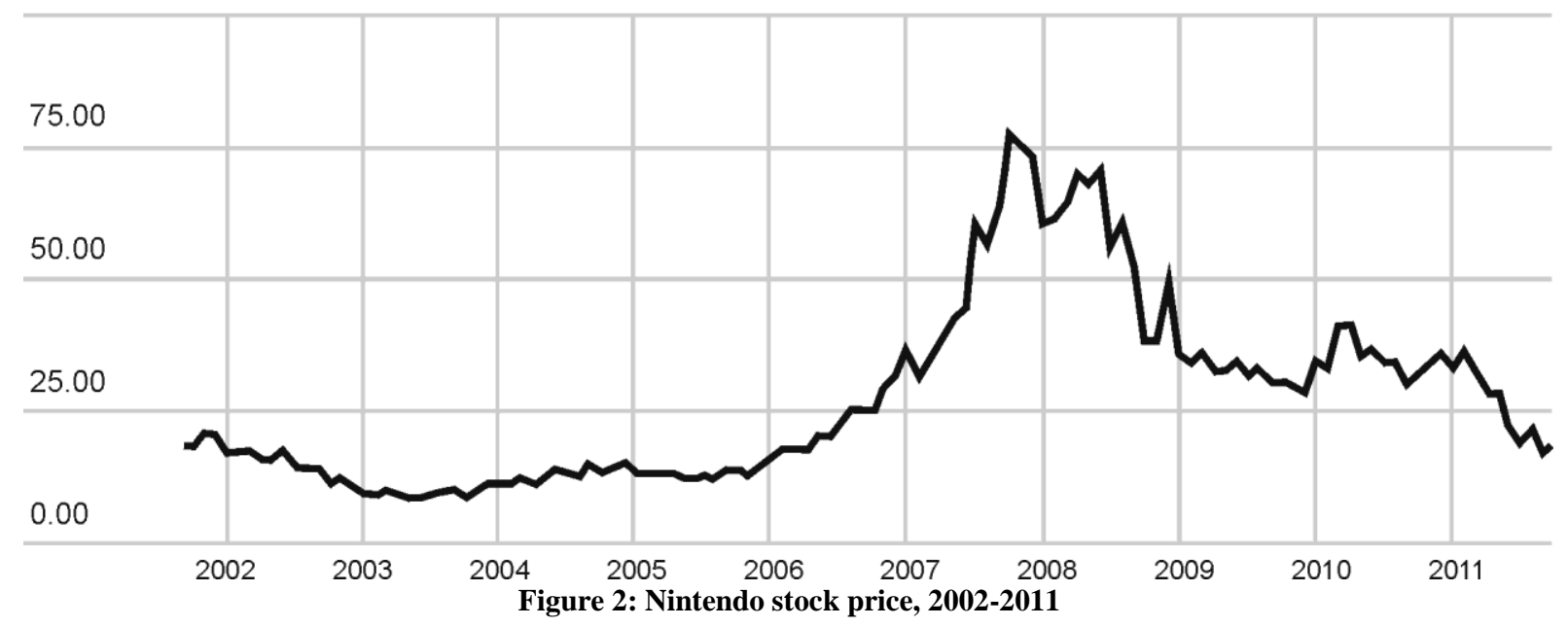

To refresh its lineup, Nintendo launched a new handheld in February 2011 (in March in North America). While looking somewhat similar to the older DS, the Nintendo 3DS had a unique capability of producing a 3dimentional image without requiring special glasses. 
The launch of the 3DS was the most successful new product launch in Nintendo's history, yet sales fell short of expectations: only 3.6 million units were sold in the first quarter of 2011 instead of planned 4 million. But worse off, in the second quarter sales literally plummeted - from 3.6 million down to 710 thousand. The main problem with such slowdown was not the loss of profits from hardware, but the loss of potential sales of games - the main source of profits for gaming consoles manufacturers including Nintendo. The company slashed the device price in response - from $\$ 250$ to $\$ 170$ (prices in the U.S.A.) - but had to slash the profit outlook for the year as well.

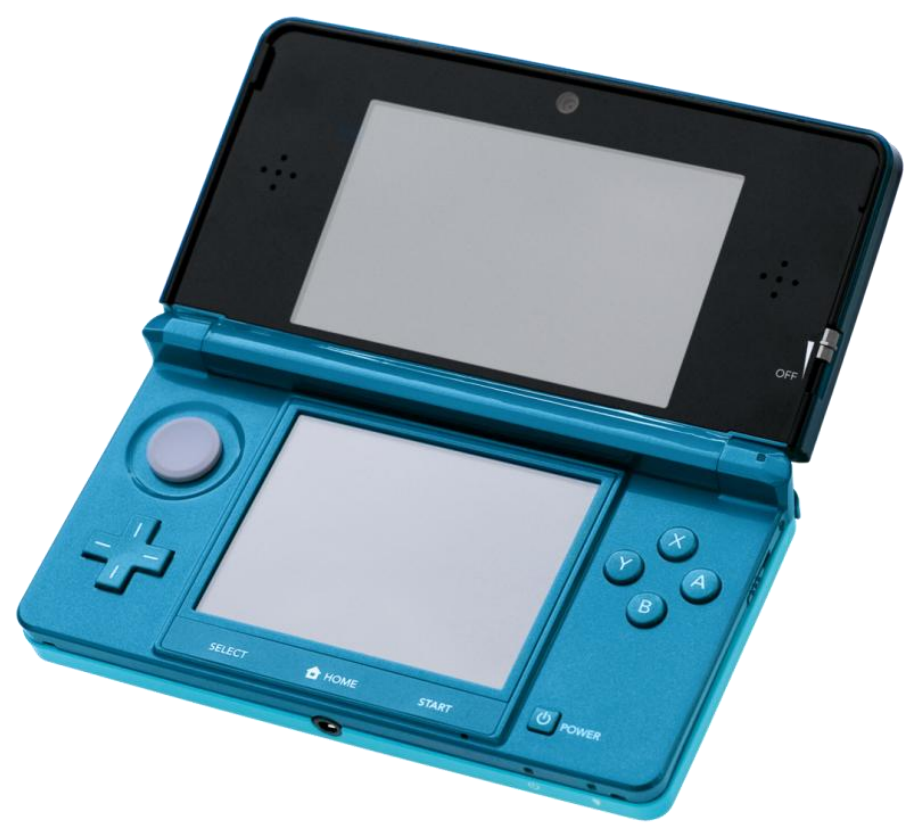

Figure 3: Nintendo 3DS (Source - Wikipedia.org)

The sales of Wii were also declining rapidly: compared to the first quarter of 2010, the sales in the first quarter of 2011 dropped from 3.04 to 1.76 million units. The sales of Nintendo DS (a conventional hand-held) also dropped from 3.15 to 1.44 million units.

This was the reflection of the overall decline of the traditional gaming industry in 2010-11. Yet Nintendo's rivals seemed to suffer less: at the time when Nintendo was announcing its losses, Microsoft reported a 30\% increase in quarterly revenue for the division manufacturing the Xbox 360.

In June 2011 Nintendo announced a successor to the Wii - the Wii U. The new console was expected to be launched in 2012 and possessed the required HD capability. It also featured an innovative controller with a 6.3-inch touch screen similar to Apple's tablets. Mr. Iwata, Global President of Nintendo stated at the presentation that the new product will target not only casual but hardcore players as well. The stock price went down even further.

These unfortunate developments that can be presented as a Part 3 of the case show the danger of placing all bets on a single segment of a market. The original Wii product with its low quality graphics was not intended for hard-core players, becoming all but irrelevant for them. The company's focus was on the low-involvement, casual gamers. Those demanded less pricey systems, less expensive games, short learning cycles for players, and the graphics was not a priority. But the launch and fast acceptance of the iPhone in 2007 and the iPad in 2010 gave casual gamers a perfect alternative. While both devices were pricier, they were more universal and in case of the iPhone took care of a basic need not related to gaming. By 2010 both platforms had thousands of free or very cheap games available ( $\$ 1-\$ 5$ compared to $\$ 20-\$ 40$ for a typical Nintendo game) plus they could be used to play online, in a social environment - something that Nintendo completely neglected. 
With screens of smartphones getting larger and tablets becoming more widespread, the relevance of a dedicated console for casual gamers - mainly adults, but kids as well - was rapidly declining. So did the sales, profits, and the stock market's faith in the future of Nintendo.

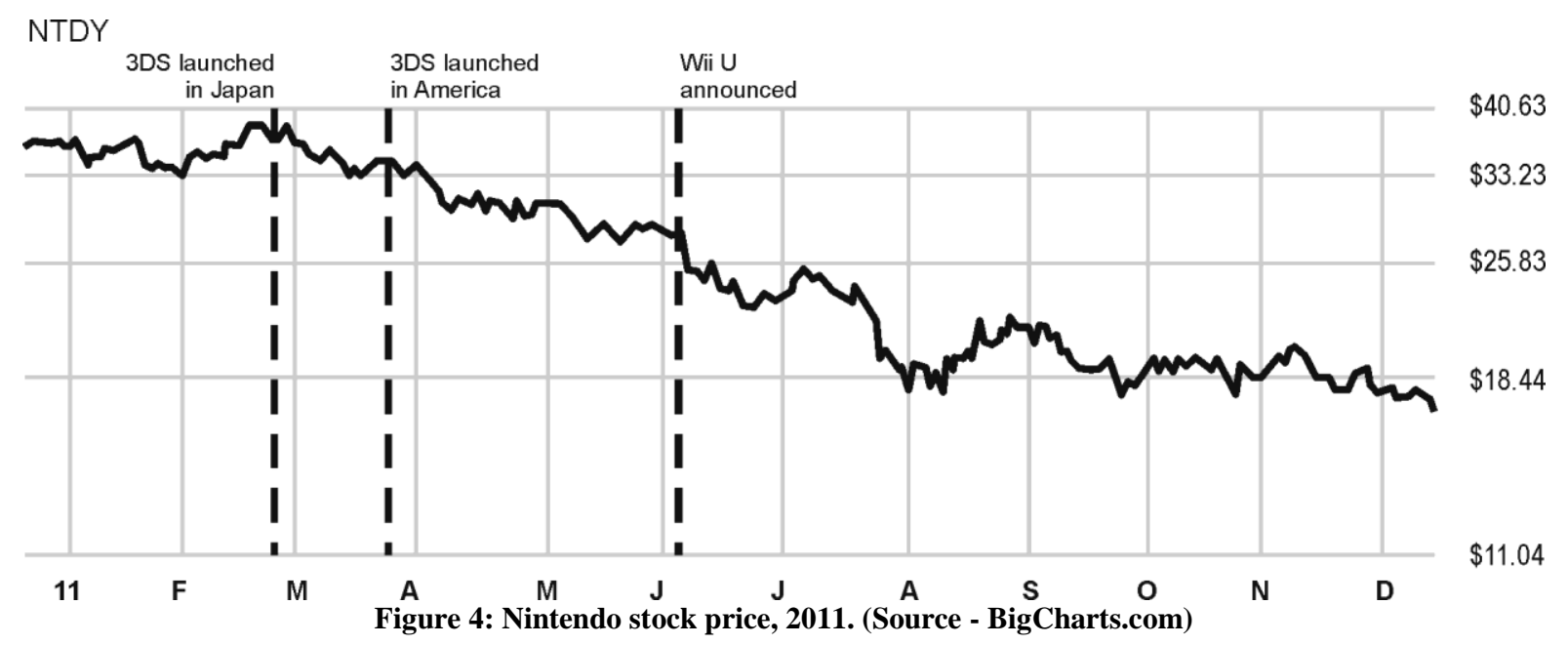

The stated intention to target the hard-core audience was another move that probably was inevitable, but did Nintendo little good: the company was announcing that it was going to return into the fight that it has lost once. All the image problems that made it so difficult for the company to establish its relevance for hard-core gamers remained, in fact they were amplified by years of pursuit of other segments. The perspective of Nintendo fighting to stay relevant in two vastly different markets - casuals and hard-cores - made the future of the company too risky for investors, precipitating the stock price drop despite the announcement of the product that was generally praised by gaming industry experts as innovative.

\section{REFERENCES}

1. $\quad$ Arnst, C. (2006). Chicken Soup for The Aging Brain. [Article]. BusinessWeek(4002), 94-96.

2. Bremner, B. (2006). Will Nintendo's Wii Strategy Score? [Article]. BusinessWeek Online, 22-22.

3. Hartley, M. (2011, June 7). Nintendo kicks off next generation of console wars with Wii U, Financial Post.

4. Kane, Y. I. (2006, July 25). Nintendo's Net Receives Lift From Brisk DS Sales, Teh Wall Street Journal.

5. Kane, Y. I., \& Wingfield, N. (2006, November 2). Amid Videogame Arms Race, Nintendo Slows Things Down, The Wall Street Journal.

6. Loftus, T. (2011). Nintendo Fails to Level Up. Retrieved from http://blogs.wsj.com/digits/2011/10/27/techtoday-nintendo-fails-to-level-up/

7. Mann, J. (2006). Nintendo expects supply shortage of Wii Retrieved November 1, 2006, from http://www.techspot.com/news/23415-nintendo-expects-supply-shortage-of-wii.html

8. $\quad$ Sanchanta, M. (2007, September 12). Nintendo's Wii takes console lead, Financial Post.

9. Wakabayashi, D. (2011, October 28). Nintendo Dragged Down by Sluggish Wii Sales, The Wall Street Journal.

10. Wingfield, N. (2011, July 29). Nintendo: Apple's Latest Prey, The Wall Street Journal.

11. Wingfield, N., \& Wakabayashi, D. (2011, June 8). Next Wii to Play Off the Tablet Craze, The Wall Street Journal.

12. Woo, S. (2011). Nintendo Game Chief Sees Better Times Ahead. Retrieved from http://blogs.wsj.com/digits/2011/12/08/nintendo-game-chief-sees-better-times-ahead/ 